\title{
Application of Atomic and Molecular Physics in the Atmosphere
}

\author{
Mohamed Habib Ahmed Elkanzi ${ }^{1}$, Abdelnabi Ali Elamin ${ }^{2}$ \\ ${ }^{1}$ Department of Astronomy and Meteorology, Faculty of Science and Technology Omdurman Islamic University, Omdurman, Sudan \\ ${ }^{2}$ Department of Physics, Faculty of Science and Technology Omdurman Islamic University, Omdurman Sudan
}

Email address:

kanzi_sa@yahoo.com (M. H. A. Elkanzi), aelamain@yahoo.com (A. A. Elamin)

\section{To cite this article:}

Mohamed Habib Ahmed Elkanzi, Abdelnabi Ali Elamin. Application of Atomic and Molecular Physics in the Atmosphere. American Journal of Astronomy and Astrophysics. Vol. 4, No. 6, 2016, pp. 89-92. doi: 10.11648/j.ajaa.20160406.14

Received: November 3, 2016; Accepted: December 5, 2016; Published: January 6, 2017

\begin{abstract}
The most important of a long term changes in structure of the atmosphere due to the concentration of various species in the upper atmosphere. The gaseous or vaporous shell that surrounds the earth. When early man first sought to understand his physics environment, his greatest awe surely concerned the sun, moon, planets, and stars (which became the basis of the science of astronomy or astrophysics), and next he wondered at the winds and storms, rain and snom, ironment, his greatest awe surely concerned the sun, moon, planets, and stars (which became the basis of the science of astronomy or astrophysics), and next he wondered at the winds and storms, rain and snow, clouds, lighting, and thunder that collectively made up his weather. The Greek root atmos, meaning air or vapor, originally derived from the word for winds. The first impetus to meteorological theory was given by the puzzling behavior of the barometer in relation to the weather, but it remained for Vilhelm Bjerknes, a physics professor at Bergen, Norway, around 1900 to formulate weather systems mathematically in terms of high- and low-pressure areas, warm fronts, and cold fronts. In England, Napier Shaw began scientific research on atmospheric processes in 1885 at the Cavendish Laboratory, by 1918 weather forecasting had become a science, much as we know it today. So on. As well as the seasonal changes from summer to winter. The prevailing weather at a given location is called its climate, and climate varies with geographical latitude, terrain features, and altitude.
\end{abstract}

Keywords: Atmosphere, Atmospheric Composition, Radiation, Ionosphere, Magnetosphere, Weather

\section{Introduction}

\subsection{Atmospheric Circulation}

Two major processes drive atmospheric weather systems: the rotation of the earth and uneven heating by solar radiation. In addition, the 33.5 tilt of the earth's axis to the plane of its orbit and earth's elliptical orbit about the sun add winter and summer seasonal changes to the solar radiation received. These radiation processes are further altered by variable cloud cover, which reflects radiation that would otherwise warm the surface, and by the heat absorbed in the vaporizing of water or released by the condensation of water vapor into rain or snow. The earth's surface receives more solar radiation in the equatorial regions than at higher latitudes Air warmed near the surface rises and creates a convective circulation pattern in the upper atmosphere from the equator toward the poles. However, because the earth (and its atmosphere) is also rotating, the rate of eastward rotation is function of latitude, being about 0.7 of the equatorial velocity at latitude 45 (and 0.5 at latitude 60). This motion superposes a shift to the right on the wind pattern in the Northern Hemisphere (and to the left in the Southern Hemisphere). The general circulation of the atmosphere is further modified by uneven local heating and by differences in neat absorption of oceans and land. There are general regions of prevailing winds, in the Northern Hemisphere (and, in reversed direction, in the Southern Hemisphere). Near the equator the creates a region of equatorial calms or doldrums. Between the equator and latitude $30^{\circ} \mathrm{N}$ is a region of prevailing northeast trade winds. Between latitude $30^{\circ}$ and $60^{\circ}$ is a region of prevailing westerly winds. Between these two regions are the so-called horse latitudes, another region of calm, where the air is sinking and warmed adiabatically.

Above latitude $60^{\circ}$ is a region of polar easterlies. At the surface, the moving air forms into whirling masses of high- 
pres -sure cells, called highs, or anticyclones (which circulate clockwise in the Northern Hemisphere); and lowpressure cells, called lows or cyclones (which circulate counter clock wise). Highs generally bring fair weather and lows unsettled weather.

Although weather phenomena are atmospheric processes, the field of physical meteorology is now developed to the point that it is considered separate from atmosphere physics, which is ordinarily restricted to those phenomena other than weather.

\subsection{Atmosphere Chemistry}

The production of electrons and ions is balanced by loss processes in quasi- steady - state ionosphere. The loss processes usually involve reduction of the photo-electron to thermal energies followed by ion- electron recombination or electron attachment.

Typical processes might be represented as follows:

$$
\begin{gathered}
\mathrm{NO}^{+}+e^{-} \rightarrow \mathrm{N}+\mathrm{O} \text { (Dissociative recombination) } \\
\mathrm{O}^{+}+e^{-} \rightarrow \mathrm{O}+\mathrm{hv} \text { (Radiative recombination) } \\
\mathrm{O}_{2}+\mathrm{O}_{2}+e^{-} \rightarrow \mathrm{O}_{2}^{-}+\mathrm{O}_{2} \text { (Three- body attachment) }
\end{gathered}
$$

The physics of the electron in the upper atmosphere is very important when considering radio transmissions. However, with the advent of sampling opportunities by rocket soundings atmosphere chemists have become increasingly interested in the chemistry of the upper atmosphere. So the positive charge in the F- layer of the ionosphere is largely carried by $\mathrm{O}^{+}$while at lower levels it is more likely to be present on $\mathrm{NO}^{+}, \mathrm{O}^{+}, \mathrm{O}_{2}^{+}$and lower down in the atmosphere, the hydrated proton. The complete picture of positive ion chemistry is long way off even through many hundreds of reactions are often used in descriptions. The $\mathrm{D}-$ region is particularly complex because of the presence of an extensive array of negatively charged poly- molecular hydrates of water. The E- region is interesting because it sometimes shows thin sporadic layers that appear to be derived from metal ion chemistry in mid- latitudes. Significant increases in the intensities of these layers are observed in response to meteor showers so and extra- terrestrial origin for the metal ions is very likely. Typical reactions are:

$$
\begin{aligned}
M g+h v & \rightarrow \mathrm{Mg}^{+}+e^{-} \\
\mathrm{Mg}^{+}+\mathrm{O}_{2}+M & \rightarrow \mathrm{MgO}_{2}^{+}+M \\
\mathrm{Mg}^{+}+\mathrm{O}_{3} & \rightarrow \mathrm{MgO}^{+}+\mathrm{O}_{2}
\end{aligned}
$$

Where $M$ is a third body. The first reaction produces electron but subsequently the positively charged metal and metal oxide species can react with the electron.

If small meteor affect the chemistry of the ionosphere it is not surprising that the effects of human activities are also detectable. When Skylab was launched it was the first time a large booster operated in the upper portion of the ionosphere $(190 \mathrm{Km})$. Electron densities were lowered over a radius of $1000 \mathrm{Km}$ around the flight path of the rocket.
This electron - hole may be understood by considering the fact that some $1.2 \times 10^{31}$ molecules of water and hydrogen were released during the ionosphere portion of the flight. Oxygen ions $\left(\mathrm{O}^{+}\right)$are normally removed from the ionosphere through reaction with Oxygen and nitrogen:

$$
\begin{aligned}
& O^{+}+\mathrm{O}_{2} \rightarrow \mathrm{O}_{2}+\mathrm{O} \\
& \mathrm{O}^{+}+\mathrm{N}_{2} \rightarrow \mathrm{N}_{2}+\mathrm{O}
\end{aligned}
$$

But the reactions involving hydrogen or water are known to be about a thousand times faster. This can lead to a considerable reduction in the concentration of electrons though the reactions:

$$
\begin{aligned}
& \mathrm{O}^{+}+\mathrm{H}_{2} \mathrm{O} \rightarrow \mathrm{H}_{2} \mathrm{O}^{+}+\mathrm{O} \\
& \mathrm{O}^{+}+\mathrm{H}_{2} \rightarrow \mathrm{OH}^{+}+\mathrm{H}
\end{aligned}
$$

Followed by:

$$
\begin{aligned}
& e^{-}+\mathrm{H}_{2} \mathrm{O}^{+} \rightarrow \mathrm{H}_{2}+\mathrm{O} \\
& e^{-}+\mathrm{H}_{2} \mathrm{O}^{+} \rightarrow \mathrm{OH}+\mathrm{H} \\
& e^{-}+\mathrm{OH}^{+} \rightarrow \mathrm{O}+\mathrm{H}
\end{aligned}
$$

\subsection{Atmospheric Density}

Except for highly variable aerosol and water- vapor content, the lower atmosphere behaves as a homogeneous mature of the constituents indicated in Table I, and its press directly proportional to the absolute temperature (Charles's lave and directly proportional to the sum obtained by adding.

Table 1. Mass of the atmosphere and its constituents.

\begin{tabular}{llll}
\hline Substance & $\begin{array}{l}\text { Volume percentage } \\
\text { dry air }\end{array}$ & $\begin{array}{l}\text { Molecular } \\
\text { weight }\end{array}$ & $\begin{array}{l}\text { Total mass } \\
(\mathbf{k a} \times \mathbf{1 0} \text { ") }\end{array}$ \\
\hline $\begin{array}{l}\text { Total atmosphere } \\
\text { Dry air }\end{array}$ & 100.00 & $28.97 "$ & 51300000 \\
Nitrogen & 78.09 & 28.02 & 38648000 \\
Oxygen & 20.95 & 32.00 & 11841000 \\
Argon & 0.93 & 39.88 & 655100 \\
Water Vapor & & 18.02 & 130000 \\
Carbon dioxide & 0.03 & 44.00 & 23320 \\
Neon & 0.0018 & 20.0 & 636 \\
Krypton & 0.0001 & 82.9 & 146 \\
Helium & 0.00053 & 4.00 & 37 \\
Ozone & & 48.00 & 30 \\
Xenon & 0.000008 & 130.2 & 18 \\
Hydrogen & 0.00005 & 2.02 & 2 \\
\hline
\end{tabular}

"Effective gether the molecular weights of the constituents, each multiplied the ratio of its partial pressure to the total pressure (Avogadro's law). The average atmospheric pressure at sea level is about $101.3 \mathrm{kPa}$ and the density $1.2 \mathrm{~kg} \mathrm{~m}^{-3}$ both decrease exponentially with height, and by several earth radii the density can be said to that of interplanetary space. Drag effects due to atmospheric density can generally be neglected for rockets and spacecraft more than $200 \mathrm{~km}$ above the surface; satellites in such orbits have lifetimes of several years. 


\subsection{Atmosphere Radiation}

The sun is a huge gaseous sphere (about $1.39 \times 10^{5} \mathrm{~km}$ in diameter) whose temperature at the radiation surface is about $6000 \mathrm{k}$. The radiant solar energy incident on the earth outside the atmosphere is about $1390 \mathrm{Wm}^{-2}$ (with an annual variation of $\pm 3.5 \%$ because of the ellipticity of the earth's orbit). If the earth had no atmosphere, but were a rotating sphere with an overall reflectivity similar to that of the moon, it would absorb this solar radiation until it had warmed up to an average temperature of just over $200 \mathrm{k}$, for then it would be radiating blackbody radiation to the $4 \pi$ sphere of free space at about the same rate radiation is received from the sun.

The atmosphere provides a warm thermal blanket around the earth, because it is largely transparent to the incoming $6000-\mathrm{k}$ blackbody radiation, which is mostly at wavelengths stituents ozone, carbon dioxide, and water have strong wavelength infrared radiation emitted by the earth. As a result, the surface temperature of the earth in the temperate regions warms to about $300 \mathrm{k}$.

Some of the oxygen molecules of the lower atmosphere diffuse upward but are then dissociated into atomic oxygen by incident solar ultraviolet radiation. Atomic oxygen strongly absorbs all solar radiation shorter than $1850 \mathrm{~A}$. There is a region about $30 \mathrm{~km}$ above the earth's surface where the up-ward-diffusing molecular oxygen and the downward-diffusing atomic oxygen react to form a tenuous layer of ozone. The ozone molecule strongly absorbs all radiation below about $3150 \mathrm{~A}$, thereby screening out solar ultraviolet radiation that would otherwise be lethal to the surface. The absorption of radiation by ozone at $30 \mathrm{~km}$ and by atomic oxygen and nitrogen higher in the atmosphere is the mechanism responsible for the thermal structure of the atmosphere.

\subsection{Atmosphere Optics}

The most important optical effects of the atmosphere are the screening out of lethal ultraviolet solar radiation and the raising of the radiation temperature of the earth by trapping infrared thermal radiation. In addition there are awide variety of curious optical effects that are interesting physics, but not of practical importance or dangerous to life: such phenomena as mirages, rainbows, halos, sun dogs, glories, and heiligenschein. These are caused by temperature inversions, scattering by aerosols, fog or ice crystals, and so on phenomena; today many of these effects can be seen by airplane travelers. M. Minneart and W. J Humphreys treat the physics of these phenomena.

\section{The Magnetosphere}

In addition to its atmosphere, the earth is surrounded by a magnetic field. The main field originates the earth. The magnetic axis is inclined at an angle of about $11^{0}$ to the axis of rotation. The field strength at the surface is about $0.6 \mathrm{G}$ in the Polar Regions and $0.3 \mathrm{G}$ in the equatorial region. Field originating outside the earth are much more variable and are weaker; in general, they last a few days or less. These fields are caused by electric-current systems in the lower ionosphere. During magnetic storms these fields may have fluctuations of $5 \%$ of the main field in auroral zones. At altitudes of several earths interaction between the main field and corpuscular radiation from the sun (the solar wind) become more important. Magnetic disturbances can interrupt communications and affect the behavior of spacecraft; there are also linked to the phenomenon of auroras in the highaltitude ionosphere.

\section{Incoming and Outgoing Energy Flues}

The overall temperature of plant was determined by a balance between incoming and outgoing energy fluxes. In a steady state, the planet must radiate as much energy as it absorbs form the sun the earth, radiating as a blackbody at an effective temperature, $T_{E}$ obeys the Stefan - Boltzmann law in which the energy emitted is expressed as $\sigma T_{E}^{4} 4 \pi R_{E}^{2}$ where $\sigma$ Stefan - Boltzmann constant, and $\mathrm{R}_{\mathrm{E}}$ the radius of the earth. An equation expressing the equality of energy absorbed and energy emitted can be written as

$$
F_{s} \pi R_{E}^{2}(1-A)=\sigma T_{E}^{4} 4 \pi R_{E}^{2}
$$

Where $\mathrm{A}$ is the ablbedo of the earth (the fraction of solar radiation reflected from, rather than absorbed by, the Earth). Fs is the solar flux at the edge of the Earth's atmosphere and $4 \pi R_{\mathrm{E}}^{2}$ is the Earth's area normal to the solar flux. Solving this equation for TE one obtains TE approximately $255 \mathrm{~K}$ ($\left.18^{\circ} \mathrm{C}\right)$.

The Sun which has a surface temperature of approximately $6000 \mathrm{~K}$, emits most of its radiation in the $0.2-4.0 \mathrm{pm}$ region of the spectrum (2000-40000A0). The upper atmosphere Earth (thermosphere, mesosphere and stratosphere) absorbs all solar radiation short wave of 32 $\mathrm{nm}$. The atmosphere of the Earth absorbs only weakly in the visible region of the spectrum where the solar flux peaks.

The Earth, with an effective radiating temperature of $255 \mathrm{~K}$ emits mainly long - wavelength radiation in the 4-100 pm regions. Molecules naturally present in the atmosphere in trace amounts, such as carbon dioxide, water and methane, absorb strongly in this wavelength region radiation coming from the Earth is thus absorbed, reradiated back to the surface and thermalized through collisions with the ambient gas. This trapping of the radiation produces an additional warming of $33 \mathrm{~K}$.

Thus the mean surface temperature of the Earth is $288 \mathrm{~K}$, not $255 \mathrm{~K}$ (as found for TE above). This effect of the Earth's atmosphere is known as the greenhouse effect. The greenhouse effect is what makes Earth habitable for life as we know it. Gases, both natural and man - made, which absorb strongly in 4-100pm regions, are known collectively as greenhouse gases. 


\section{References}

[1] Astrophysical Journal, published by the University of Chicago Press, Chicago. III.

[2] Aastrophysical and Space, published by Reidel Published Dordrecht, The Netherlands.

[3] Astronomy and Astrophysical by Springer- Verlag. Berlin. Manthly Notices of the Royal Astronomical Society, published by Biackwell Scicentific Publications. Oxford. England.

[4] N. Asheroft and D. Mermin, Solid Statr Physics, Hoit Rinehart \& Winston. New York 1976.

[5] F. Seitz. Modern Theory of Solids McGraw-Hill, New York, 1940.

[6] R. A Anthes, H. A. Panofsky. J. J Cahir, and A. Rango, the At mosphere. Merrill Publishing Co. New York, 1978.

[7] J. T. Houghton, The Physics of Astmospheres, $2^{\text {nd }}$ ed. Cambridge University Press, Cambridge, 1986.

[8] T. E. Graedel and P. J. Crutzen, Atmospheric Change: An Earth System Perspective (W. H. Freeman, New York, 1993): J. Houghton, Global Warming: The Complete Brefing (Lion Publishing Oxford, 1994).

[9] R. G. Roble, in Encyclopedia of Applied physics (VCH Publishing, Oxford, 1994), Vol, 2, pp, 201-224.

[10] Peter, B. L. Air composition and Chemistry. London 2011, Cambridge University Press.

[11] Steven, A. A., Meteorology Understanding the Atmosphere, USA 2008, Thomson Brook lcole. 